\title{
The exposure and time spent on various audio-visual media devices by children in Delhi, India
}

\author{
Bhavna Anand ${ }^{1}$, Singam Lakshmi Narasimha Reddy ${ }^{2}$, Satish Kumar Meena ${ }^{3}$, Manas Pratim Roy ${ }^{4}$ \\ From ${ }^{1}$ Specialist, ${ }^{2}$ Resident, ${ }^{3}$ Associate Professor, Department of Pediatrics, Vardhman Mahavir Medical College and Safdarjung Hospital, ${ }^{4}$ Deputy \\ Assistant Director General (NCD), DGHS, MoHFW, Nirman Bhawan, New Delhi, India
}

\begin{abstract}
Background: The advancement in the technology and availability of mobile devices has rendered children more vulnerable to audiovisual media devices. However, studies with a focus on the exposure of children to such devices are a handful, particularly from the developing countries. Objectives: This study investigates the exposure of children to various audio-visual media devices. Methods: This cross-sectional, questionnaire-based study included 354 children (56.5\% boys and $43.5 \%$ girls) between 6 months and 12 years who came for a wellness visit or vaccination at a tertiary care hospital in New Delhi, India, from August 2016 to July 2017. The study questionnaire was adopted from Zero to Eight Common Sense Media 2013 nationwide survey (USA). Results: All study children had access to mobile devices ( $75 \%$ to smartphones, and $25 \%$ to ordinary mobile phones); $93.5 \%$ had access to television and $14.4 \%$ had access to computers. For television, the average daily screen time was $>2 \mathrm{~h}$ in $38.4 \%$ of children. It was significantly more in the age group of $2-8$ years, female gender, and urban background $(\mathrm{p}<0.05)$. For mobile phones, maximum exposure was seen in the age group of 5-8 years with 19\% children having screen time of $>2 \mathrm{~h} /$ day. Conclusion: Many of the study children have daily screen time for more than $2 \mathrm{~h}$, warranting the need of specific guidelines for optimal media usage by children, especially for developing countries like India.
\end{abstract}

Key words: Audio-visual media device, Mobile-media, Screen time

$\mathrm{T}$ The exposure of children to various audio-visual media devices such as television and computers remains a concern for many years. Due to advances in technology, nowadays, more sophisticated and handy devices such as smartphones and tablets are easily available to children. According to a recent survey in USA, mobile devices are becoming the preferred media choice for children because of their screen size, mobility, interactive capability, wide spectrum of entertainment, and decreasing costs. The exposure of children to these media devices is universal in developed countries [1]. Such studies are only a few in developing countries like India.

However, there is parallel concern on the impact of smart phone on young minds [2]. The growing concern for the long-term impact of screen time on health across the lifespan suggests the need to focus on all screen time. Teachers, parents, health-care providers, and child development experts all agree that the use of media devices by children can have a profound impact, both positive and negative, on learning, social development, and behavior [3]. The American Academy of Pediatrics (AAP) recommends that

\section{Access this article online}

Received - 01 September 2020

Initial Review - 17 September 2020

Accepted - 17 October 2020

DOI: 10.32677/IJCH.2020.v07.i10.003 children under 2 years of age should have no screen exposure and that parents of children older than 2 years should limit their children's exposure to $<2 \mathrm{~h}$ /day [4]. Similar recommendations were subsequently formulated by the Australian Department of Health and the Canadian Pediatric Society [5, 6]. A meta-analysis from India underscored negative health risks on toddlers and children from smart phone addiction [7]. With this background, the study aims to examine the exposure and time spent on various audiovisual media devices by children in a metropolitan city in India.

\section{MATERIALS AND METHODS}

This was a cross-sectional study done from August 2016 to July 2017 at a tertiary care hospital in Delhi, India. The children between 6 months and 12 years who visited the hospital for wellness visit or vaccination were enrolled after informed and written consent from their parents. Consecutive sampling was done. Sick children were excluded from the study. The prevalence of mobile media exposure was $73 \%$ from a pilot study in the department. Assuming 5\% as allowable error, using formula $\mathrm{n}=4 \mathrm{pq} / \mathrm{d}^{2}$, the sample size calculated was 316 children where $\mathrm{p}$ is prevalence; $\mathrm{q}$ is $(100-\mathrm{p})$, and $\mathrm{d}$ is allowable error, here $5 \%$.

Correspondence to: Dr. Satish Kumar Meena, Department of Pediatrics, Vardhman Mahavir Medical College and Safdarjung Hospital, New Delhi - 110 029, India. E-mail: meenask1980@gmail.com

(C) 2020 Creative Commons Attribution-NonCommercial 4.0 International License (CC BY-NC-ND 4.0). 
We developed a 30-item questionnaire (in English and Hindi) adopted from Zero to Eight Common Sense Media 2013 nationwide survey (USA) [3]. All the questions were explained to the parents in their own language. The demographic profile including child's age in years, gender, parental education, and annual family income was recorded. The parents were asked about the availability of audio-visual media devices in their household and child's access to it. We categorized these media devices into three major categories, namely, television, laptop/desktop, and mobile devices such as ordinary mobile phones, smartphone, and tablets.

To determine the screen time and content accessed, we asked about the specific media type separately in detail. If there is a television in the household, we asked about daily screen time, whether the child is watching it with parents/siblings; type of program being watched; most favorite program, and coactivities along with television watching such as eating, doing school homework, and playing with mobile phone or toys. If there is a computer device (laptop/desktop) at household then we enquired about whether the child has access to it or not; if yes, for what purpose; time spent with the device and parental supervision. If there is a mobile device, then we asked about the type of mobile device in family, child's access to it, time spent with the device in a day and most common activity/program being watched. Clearance was taken from Institutional Ethical Committee.

Data were recorded on the pre-designed format and managed on an excel spreadsheet. Continuous variables were analyzed by mean and standard deviation while categorical variables were analyzed by Chi-square and Fischer's exact test. Factors determining exposure were analyzed by bivariate and multivariate regression, followed by an assessment of the fit of the model. $\mathrm{p}<0.05$ was taken as significant. IBM SPSS 2017 software was used for statistical analysis.

\section{RESULTS}

A total of 354 children were enrolled in the study; $56.5 \%$ were male and $43.5 \%$ female. The mean age was $3.96 \pm 2.87$ years. For better understanding of the pattern of the exposure, we divided the children in 4 age groups based on their interactive capabilities with these devices, 6 months -2 years (31.2\%); $2-5$ years (33.8\%); 5-8 years $(26.8 \%)$, and $8-12(8.2 \%)$ years. Most of them were from urban area (84.2\%). Parental education characteristics also reflected literacy levels of the general urban population of the country. The children from low-income groups outnumbered the other categories significantly (Table 1).

All the study population had access to handheld mobile devices ( $75 \%$ to smart phones, and $25 \%$ to ordinary mobile phones); $93.5 \%$ had access to television sets and $14.4 \%$ had access to computers. For television, the average daily screen time by $42 \%$ children was $1-2$ $\mathrm{h}$ and another $38.4 \%$ children had screen time of $>2 \mathrm{~h} /$ day (Fig. 1). The average screen time for television across the age groups also remained the same. About $78 \%$ children like to watch television with parents. Among various programs watched by children, cartoons $(92.3 \%)$ were the most preferred, followed by movies and songs (27.9\%), entertainment shows (17.2\%), and sports (6.7\%), (Fig. 2).
Table 1: Demographic profile and socio-economic status of the study population $(n=354)$

\begin{tabular}{lc}
\hline Variables & Number, $\mathbf{n}(\mathbf{\%})$ \\
\hline Age & $3.96 \pm 2.87$ years (Mean \pm 2 SD) \\
Boys & $200(56.5)$ \\
Girls & $154(43.5)$ \\
Rural & $56(15.8)$ \\
Urban & $298(84.2)$ \\
Education level & Father; Mother \\
Illiterate & $41(11.6) ; 76(21.5)$ \\
Up to 5th & $139(39.3) ; 160(45.2)$ \\
6-12 & $149(42.1) ; 106(29.9)$ \\
Graduate & $19(5.4) ; 11(3.1)$ \\
Post graduate & $6(1.7) ; 1(0.3)$ \\
Annual income (Rupees) & \\
$<2$ lakh & $210(59.3)$ \\
$2-5$ lakh & $125(35.3)$ \\
$>5$ lakh & $19(5.4)$ \\
\hline
\end{tabular}

Cartoons were the most viewed programs among all age groups. Education, sports, action, horror, and adult programs were mainly watched by children in the age group of 8-12 years. Most common coactivity while watching television is eating $(52.5 \%)$, followed by imitating content (39\%). A small percentage of children (8.1\%) do their homework while watching television. The habit of eating while watching television decreased as age increased.

In logistic regression analysis, watching television was significantly more in children in the age group of $2-8$ years, female gender, and urban background $(\mathrm{p}<0.05)$. There was no significant correlation between children watching television with parental education and income (Table 2).

Very few households owned computers (14.4\%), of them, only one-third children $(4.8 \%)$ were using it. All the children using a computer were doing so only for entertainment purposes. Only three children were exposed to computer for $1-2 \mathrm{~h} /$ day and all of them belong to 5-8 years (Fig. 1). Nearly half of the children using a computer were under the supervision of parents. Parents of the most children thought that the supervision of the activities of a child on a computer was necessary. The most common reason for supervision is to prevent distractions from their work.

For mobile devices, $19 \%$ children in the age group of 5-8 years had daily screen time $>2 \mathrm{~h}$ and another $37 \%$ had $1-2 \mathrm{~h} /$ day on smartphone. This was significantly higher as compared to other age groups. Surprisingly, $5 \%$ of children below 2 years also had a daily screen time of $>2 \mathrm{~h}$ and another $29 \%$ of children in the same age group had a screen time of 1-2 h/day on smartphone (Fig. 1). Most of the children used it for watching videos and gaming. The parents own these devices and they gave it to their children for some or other reasons.

\section{DISCUSSION}

The present study has described the exposure of children to various audio-visual media devices from low-income, urban background 


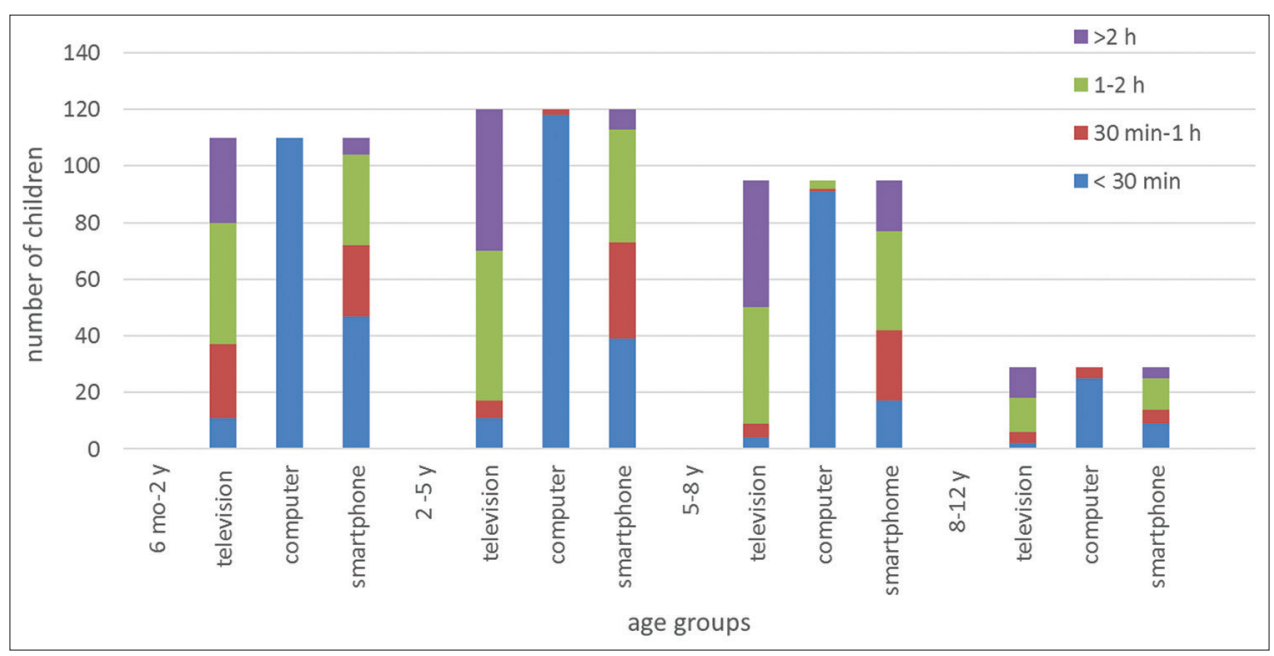

Figure 1: Bar diagram showing daily screen time by children among different age groups on various audio-visual media devices

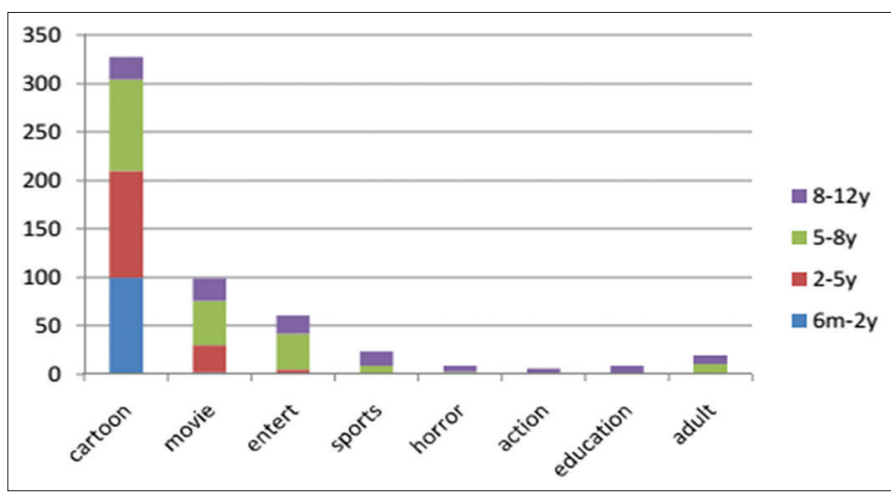

Figure 2: Bar diagram showing preferences for various type of programs being viewed on television across different age groups. $\mathrm{X}$-axis is showing type of program and $\mathrm{Y}$-axis, number of children

of India. In this study, all the children had access to mobile phones (smartphones and ordinary mobile phones), the majority had access to television sets and very few had access to computers. Almost similar access to television sets and smartphones were seen in a study from USA [1]. They observed a significant number of children were also using video consoles, tablets, computers, and the internet. Another similar study showed that media exposure of children was more to television and increased as the age advances. Almost onethird of their study population was exposed to video consoles and exposure to the computer increased as the age advances [8]. The differences in the type of devices used by children in their study and our study reflect the advances in technology, economic wellness and dependency on these devices in their countries. However, in our setup, the basic needs are entertainment and communication, so most of them had television and mobile phones with them especially in low socio-economic strata.

In this study, a significant proportion of children had daily screen time more than $2 \mathrm{~h}$ among television and smartphones; mostly for entertainment purposes. A study from South India also showed that $87 \%$ of the children were using smartphones mostly for entertainment purposes as in this study [9]. Another study from Korea suggested similar findings [10]. The screen time is significantly more in this study as compared to other previous studies probably because they are having
Table 2: Logistic regression analysis showing factors predictive of increased duration of television watching

\begin{tabular}{|c|c|c|}
\hline Age & OR (95\% C.I.) & (p-value)* \\
\hline 6 month-2 year & Referent & \\
\hline $2-5$ years & $14.2(4.5,44.6)$ & 0.00 \\
\hline $5-8$ years & $6.2(2.1,18.1)$ & 0.001 \\
\hline $8-12$ years & $1.8(0.4,6.9)$ & 0.381 \\
\hline \multicolumn{3}{|l|}{ Gender } \\
\hline Boys & Referent & \\
\hline Girls & $6.8(2.5,18.5)$ & 0.01 \\
\hline \multicolumn{3}{|l|}{ Residence } \\
\hline Rural & Referent & \\
\hline Urban & $19.4(4.5,82.3)$ & 0.00 \\
\hline \multicolumn{3}{|c|}{ Paternal education } \\
\hline Illiterate & Referent & \\
\hline Up to 5 & $0.53(0.06,4.7)$ & 0.577 \\
\hline $5-12$ & $0.5(0.04,5.4)$ & 0.574 \\
\hline Graduate & $0.36(0.0,0.9)$ & 0.998 \\
\hline Post graduate & $0.0(0.0,0.0)$ & 0.998 \\
\hline \multicolumn{3}{|c|}{ Maternal education } \\
\hline Illiterate & Referent & \\
\hline Up to 5 & $1.6(0.3,12.9)$ & 0.370 \\
\hline $5-12$ & $1.09(0.16,7.4)$ & 0.925 \\
\hline Graduate & $0.2(0.0,0.8)$ & 0.999 \\
\hline Postgraduate & $0.3(0.0,0.9)$ & 0.999 \\
\hline \multicolumn{3}{|c|}{ Annual Income (Rupees) } \\
\hline$<2$ lakh & Referent & \\
\hline 2-5 lakh & $0.047(0.012,0.18)$ & 0.00 \\
\hline$>5$ lakh & $3.5(0,4)$ & 0.998 \\
\hline
\end{tabular}

country-specific guidelines regarding daily screen time and general awareness [11-13]. In addition, possession of smart phones by most of the parents grants easy access for the children to the devices [7]. This may be a strong contributory factor for increased screen time in our study. A similar trend was observed by other studies also in western countries [1,11]. Although the AAPs recommends no use of media below 2 years and limit the 
use to $<2 \mathrm{~h}$ after 2 years of age, our study found that the significant number of children is not adhering to these recommendations.

Female gender has been a risk factor for increased television watching in this study. Probably, because males are getting more preferences toward mobile devices owned by family and females are left with the option of static device like television. In earlier studies also, the same pattern was observed [14,15]. In this study, most of the children were watching television with parents and after the age of 8 years, they preferred to watch it alone. In one study, it was seen that parents were watching television with their children more than half of the time [16]. The most frequently viewed programs by all age groups were cartoons, followed by movies and entertainment shows. Many of the children were doing other activities simultaneously along with watching television such as eating, imitating content, and doing homework contributing to increased daily television viewing hours. Similar findings were also observed by other studies $[11,17,18]$.

The access to the computer is very less in this study as compared to studies from western countries $[11,18,19]$. This can be attributed to economic differences between developing and developed countries. All the children using a computer were doing so only for entertainment purposes. Most of the children were using the computer under the supervision of parents. Most parents thought that supervision is necessary to prevent distraction of child from work. Similar observations were also seen in previous studies $[18,19]$. It is of significant note that none of the parents under study were counseled by their pediatrician regarding the effects of usage of media devices on children and parents also did not actively seek advice.

The present study has certain limitations. Being limited to a single hospital is one of them. The results cannot be extrapolated to rural areas, although a proportion of the study participants were from rural background. Still, considering the fact that the growing burden of media addiction is crippling the future citizen and there is need to highlight it in the crowded literature, this study stands out as an exceptional effort.

\section{CONCLUSIONS}

This study showed the prevalence and screen time for various audiovisual media devices by children between 6 months and 12 years of age, from an urban lower-middle-class population in Delhi, North India. Being handy, low cost, and a very common means of communication, mobile phones are increasingly preferred over other devices across all age groups. The daily screen time of more than 2/day on various audio-visual media devices was observed among all groups which is alarmingly more. It needs to be corrected and parental counseling regarding the ill effects needs to be instituted. Certain guidelines in our country need to be formulated for better and limited usage of these devices in children. For that, future studies should explore both qualitative and quantitative aspects of such exposure to electronic media in children.

\section{REFERENCES}

1. Kabali H, Irigoyen M, Davis RN, Budacki J, Mohanty S, Leister K, et al. Exposure and use of mobile media devices by young children. Pediatrics 2015;136:1044-50.

2. Demirci K, Orhan H, Demirdas A, Akpinar A, Sert H. Validity and reliability of the Turkish version of the smartphone addiction scale in a younger population. Klinik Psikofarmakol Bulteni 2014;24:226-34.

3. Rideout V, Saphir M, Pai S, Rudd A. Zero to Eight: Children's Media Use in America 2013, Common Sense Media; 2016. Available from: https://www. commonsensemedia.org/research/zero-to-eight-childrens-media-use-inamerica-2013. [Last accessed on 2016 Jun 02].

4. American Academy of Pediatrics. Children, adolescents, and the media. Pediatrics 2013;132:958-61.

5. Australian Government Department of Health and Aging. Move and Play Every Day, National Physical Activity Recommendations for Children 0-5 Years; 2010. Available from: http://www.dhhs.tas.gov.au/_ data/assets/pdf file/0008/78812/pa_rec_0-5_yo_-_q_and_a1.pdf. [Last accessed on 2016 Jun 04].

6. Canadian Pediatric Society, Psychosocial Pediatrics Committee. Impact of Media Use on Children and Youth: Recommendations; 2016. Available from: http:/www.cps.ca/english/statements/cp/pp03-01.htm. [Last accessed on 2016 Jun 10].

7. Davey S, Davey A. Assessment of smartphone addiction in Indian adolescents: A mixed method study by systematic-review and meta-analysis approach. Int J Prev Med 2014;5:1500-11.

8. Vandewater EA, Rideout VJ, Wartella EA, Huang X, Lee JH, Shim MS Digital childhood: Electronic media and technology use among infants, toddlers, and preschoolers. Pediatrics 2007;119:e1006-15.

9. Sayid MB, Damodaran A. Children and mobile media devices. J Med Sci Clin Res 2017;5:26276-83.

10. Bae SM. The relationship between the type of smartphone use and smartphone dependence of Korean adolescents: National survey study. Child Youth Serv Rev 2017;81:207-11.

11. Christakis D, Ebel B, Rivara F, Zimmerman F. Television, video, and computer game usage in children under 11 years of age. J Pediatr 2004;145:652-6.

12. Dinleyici M, Carman K, Ozturk E, Sahin-Dagli F. Media use by children, and parents' views on children's media usage. Interact J Med Res 2016;5:e18.

13. Rideout V, Hamel E. The Media Family: Electronic Media in the Lives of Infants, Toddlers, and Pre-Schoolers. San Francisco: Kaiser Family Foundation Report; 2006.

14. Randler C, Wolfgang L, Matt K, Demirhan E, Horzum MB, Beşoluk Ş. Smartphone addiction proneness in relation to sleep and morningnesseveningness in German adolescents. J Behav Addict 2016;5:465-73.

15. Lee H, Seo MJ, Choi TY. The effect of home-based daily journal writing in Korean adolescents with smartphone addiction. J Korean Med Sci 2016;31:764-9.

16. Zimmerman F, Christakis D, Meltzoff A. Television and DVD/video viewing in children younger than 2 years. Arch Pediatr Adolesc Med 2007;161:473-9.

17. Huston A, Wright J, Marquis J, Green S. How young children spend their time: Television and other activities. Dev Psychol 1999;35:912-25.

18. Patriarca A, di Giuseppe G, Albano L, Marinelli P, Angelillo I. Use of television, videogames, and computer among children and adolescents in Italy. BMC Public Health 2009;9:139.

19. Yeh DY, Cheng CH. Relationships among Taiwanese children's computer game use, academic achievement and parental governing approach. Res Educ 2015;95:44-60.

\section{Funding: None; Conflicts of Interest: None Stated.}

How to cite this article: Anand B, Reddy SLN, Meena SK, Roy MP. The exposure and time spent on various audio-visual media devices by children in Delhi, India. Indian J Child Health. 2020; 7(10):408-411. 